\title{
A Summary of Criticality Safety of Tank 41 Salt Dissolution In-Tank Precipitation and Extended Sludge Process
}

by

P. L. Davis

Westinghouse Savannah River Company

Savannah River Site

Aiken, South Carolina 29808

$$
\text { NOT A CONF } 3-13-98 \text { PA }
$$

A document prepared for TANK FOCUS AREA MID-YEAR REVIEW at Salt Lake City, UT, USA from 3/16/98 3/20/98.

This paper was prepared in connection with work done under the above contract number with the U.S. Department of Energy. By acceptance of this paper, the publisher and/or recipient acknowledges the U.S. Government's right to retain a nonexclusive, royalty-free license in and to any copyright covering this paper, along with the right to reproduce and to authorize others to reproduce all or part of the copyrighted paper. 


\section{DISCLAIMER}

This report was prepared as an account of work sponsored by an agency of the United States Government. Neither the United States Government nor any agency thereof, nor any of their employees, makes any warranty, express or implied, or assumes any legal liability or responsibility for the accuracy, completeness, or usefulness of any information, apparatus, product, or process disclosed, or represents that its use would not infringe privately owned rights. Reference herein to any specific commercial product, process, or service by trade name, trademark, manufacturer, or otherwise does not necessarily constitute or imply its endorsement, recommendation, or favoring by the United States Government or any agency thereof. The views and opinions of authors expressed herein do not necessarily state or reflect those of the United States Government or any agency thereof.

This report has been reproduced directly from the best available copy.

Available to DOE and DOE contractors from the Office of Scientific and Technical Information, P. O. Box 62, Oak Ridge, TN 37831; prices available from (423) 576-8401.

Available to the public from the National Technical Information Service, U. S. Department of Commerce, 5285 Port Royal Road, Springfield, VA 22161. 
Safety Engineering Department

Criticality and Radiation Transport Section

Criticality Engineering Group
N-NCS-E-0007

Revision 0

Page 1 of 10

March 13, 1997

\section{UNCLASSIFIED}

Does Not Contain Unclassified

Controlled Nuclear Information $A D C$ and REYIEYING

OFEICIAI

Date $3 / 13 / 97^{\text {(Name \& Title) }}$
KEYWORDS:

Criticality

ITP

ESP

Tank $41 \mathrm{H}$

Salt Dissolution

High Level Waste

RETENTION:

Lifetime

Nuclear Criticality Safety Analysis Summary Report:

A SUMMARY OF CRITICALITY SAFETY OF TANK 41 SALT DISSOLUTION, NN-TANK PRECIPITATION(ITP), AND EXTENDED SLUDGE PROCESSING(ESP) (U)

Author:

Criticality Safety Engineering

Reviewed by

HLWE Waste Characterization

Reviewed by

Criticality and Radiation Transport

Approved by

Criticality Safety Engineering

Approved by

ITP/ESP Engineering
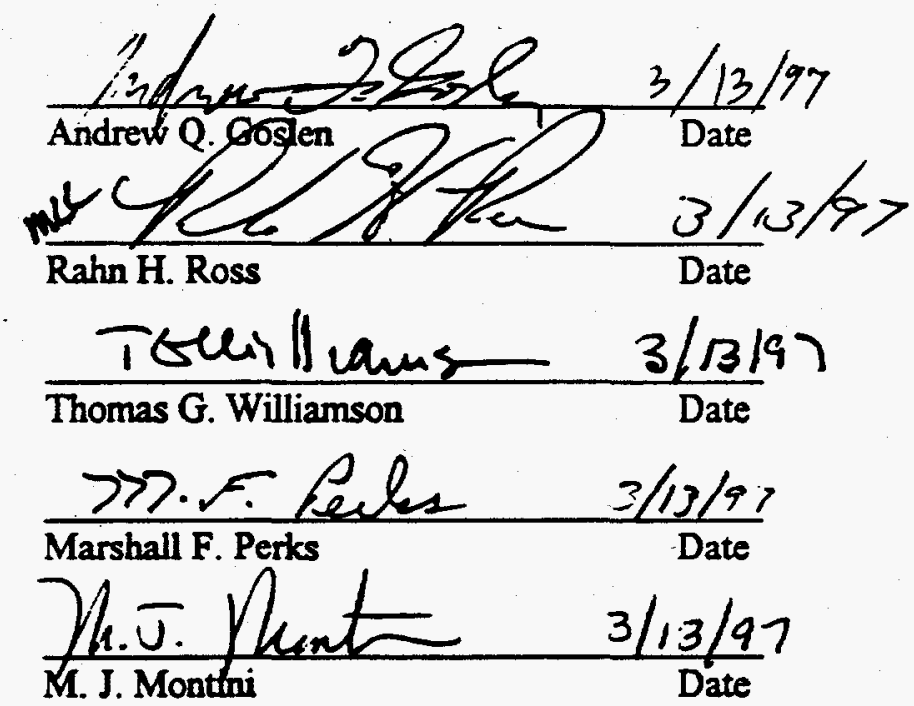

Distribution:

C. E. Apperson, 730-2B

M. S. Miller, 704-56H

M. J. Montini, 704-56H

R. L. Boyelston, 706-23C

B. L. Lewis, 703-H

A. W. Wiggins, 241-152H

W. C. Walker, 241-119H
M. C. Chandler, 703-H

M. F. Perks, 707-7F

T. G. Williamson, 730-B

R. H. Roas, 703-E

S. K. Skiles, 730-B

K. E. Hammer, 642-E

H. Hunter, WRC File Copy, 707-7F 


\section{INTRODUCTION}

In-Tank Precipitation (ITP) and Extended Sludge Processing (ESP) prepare radioactive wastes, currently stored in the Savannah River Site (SRS) high level waste tank farms, for feed to processes that will result in the permanent disposal of the wastes. ESP processes high level waste sludge to remove aluminum and soluble salts, so that the sludge is suitable for feed to the Defense Waste Processing Facility (DWPF) vitrification facilities. ITP processes salt solutions to remove most of the radioactive contamination for feed to the DWPF vitrification facilities, leaving a decontaminated salt solution suitable for disposal in the low-level waste salt-stone facility.

With the exception of salt dissolution to provide feed to ITP, the various portions of the criticality safety basis for the ITP and ESP operations are documented in numerous reports. Reference [1] summarizes the information for the ITP and ESP processes, but not for salt dissolution. This memorandum provides a summary of the current safety basis, including that for salt dissolution, in a single document.

\section{SUMMARY}

This report describes the criticality safety basis of the ITP and ESP processes, and of the salt dissolution process in Waste Tank 41H. The ITP process includes precipitation of most of the radioactive material, precipitate filtration, precipitate washing, precipitate storage, and monitoring; and storing decontaminated filtrate for feed to saltstone. The ITP facilities include the waste processing tank, the precipitate hold tank, the filter building and benzene stripper columns, waste transfer lines, and filtrate hold tanks.

The ESP process includes water washing of the sludge to remove salt, and aluminum dissolution, using sodium hydroxide solutions, to remove aluminum. The ESP facilities currently include three processing tanks, two of which may also be used as DWPF washed sludge feed tanks, steam spargers for the aluminum dissolution tank, and associated waste transfer lines. One of these tanks, Tank 42H, may also be used as an ITP blend tank when it is not used in ESP.

Salt dissolution involves the addition of water to the high level waste salt tanks, and may include agitation of the solution to enhance the salt dissolution rate.

Neutron absorbing materials inherently present in ITP and ESP make them safely subcritical under all normal and credible abnormal operating conditions. Material sampling in both ITP and ESP is used to provide additional confirmation of the continued presence of sufficient neutron absorbers.

Criticality due to adsorption on the monosodium di-titanate is not credible. The titanium in the sodium di-titanate acts as a neutron absorber, so that criticality can not occur without gross errors in both the sodium di-titanate addition and precipitate transfers. Reference [2] demonstrates the conditions necessary (but not sufficient) for criticality in the di-titanate, and shows that it is not credible for commission of the large number of processing errors necessary to cause these conditions. An important additional conservatism is present in ITP, in that the analyses do not take credit for the presence of boron. The boron is not credited because there is no limit on the minimum boron concentration. 


\section{SUMMARY (continued)}

Other potential chemical effects have also been evaluated in the ITP process. The use of tri-butyl phosphate as an anti-foaming agent in the benzene stripping columns has been shown to present no criticality concerns [3]. The dissolution of the di-titanate by oxalic acid has been evaluated to show that the dissolution will not leave a deposit of fissile materials [4].

In ESP, the sludge feed will contain sufficient quantities of iron, manganese, and other neutron absorbing elements, so that criticality is not possible, even with an infinite amount of material. Review of process flow sheets show that the average sludge composition for each high level waste tank has absorbers in excess of amounts needed to assure subcriticality [5]. The current ITP/ESP chemistry manual [6] requires that the sludge be sampled during the ESP process to reconfirm the presence of sufficient neutron poisons.

The aluminum dissolution step of ESP also dissolves low concentrations of uranium. Criticality safety for subsequent processing of the aluminum dissolution solutions has not been adequately demonstrated.

It is expected that neutron absorbing materials present in the salt will keep the salt dissolution safely subcritical. Before any given salt dissolution batch begins in tank $41 \mathrm{H}$, it will be necessary to demonstrate that that batch will have sufficient neutron poisons to remain inherently subcritical.

In all of these processes, the relative solubilities of the fissionable materials and neutron absorbers are low. The alkaline chemistry maintained in the waste tanks is an essential condition to maintain the low solubilities. Because the waste must be kept alkaline for corrosion control purposes, it is not credible that acidic conditions will be allowed to develop to the point of affecting criticality safety in the carbon steel waste tanks. For the one place where acidic conditions might be expected, in the ITP filtration system, the safety of the acidic conditions has been evaluated [4].

\section{DISCUSSION}

\section{ESP Process Description}

The ESP process treats high level waste sludge to prepare it for feed to the DWPF vitrification facility by removing soluble salt and excess aluminum. Sludge in the HLW tank farms contains more sodium than is acceptable in DWPF. Additionally, the sludge from the H-Area Canyon HM process wastes contains large quantities of aluminum. The aluminum would require increased glass volumes in DWPF to allow adequate control of the glass viscosity during processing.

Sodium salts are removed by washing the sludge in water, with the resulting salt solutions transferred to a waste evaporator feed tank. Aluminum is dissolved using steam sparging and sodium hydroxide solutions. Additional detail is available in reference [1]. 


\section{DISCUSSION (continued)}

\section{ESP Criticality Safety Basis}

The high level waste sludges contain sufficient neutron poisons to preclude criticality during any non-acidic process conditions. The high level wastes are kept alkaline due to corrosion contr $\mathbf{l}$ requirements. The high level waste storage tanks are constructed of carbon steel. A chemistry control program is required to prevent corrosion from causing tank leaks. Thus the waste is kept alkaline, independent of any criticality safety considerations. This alkaline chemistry significantly limits the actinide solubilities.

Several documents were developed to show the necessary ratio of neutron absorbers to fissile materials to assure safely subcritical conditions in infinite volume media $[7,8$, and 9].

A review of waste receipts over the lifetime of the $\mathrm{HLW}$ tank farms from 1955 to 1992 shows that the average receipts contained sufficient neutron poisons to preclude the possibility of criticality [10]. The review shows that in some months, the ratios are not sufficient by themselves to preclude criticality. But the blend of the individual transfers from the storage tanks is safely subcritical in each of the HLW tanks that can feed sludge to ESP [5].

The F-Area wastes and the early H-Area wastes were generated by the PUREX process. The process included the use of iron and manganese compounds in sufficient quantities that the average waste would be safely subcritical. The iron and manganese oxides provide sufficient neutron absorption to keep the waste subcritical. In addition, the uranium in the PUREX process was depleted in ${ }^{235} \mathrm{U}$, so that the ${ }^{238} \mathrm{U}$ by itself would provide sufficient neutron absorption to preclude criticality.

Beginning in 1959, H-Area Separations facilities started the HM process. The high-heat, highlevel waste generated by this process generally contained sufficient iron and sufficient manganese to preclude criticality. During 85 of 404 months, the HM process high-heat waste did not contain sufficient neutron absorbers. These materials blended with other waste in the receipt tanks so thal: the mixture is safely subcritical. The low-heat high-level waste streams for the HM process did not always contain sufficient iron and manganese to ensure a safely subcritical sludge. But the bulk sludge in each of these low heat waste receipt tanks did contain sufficient neutron poisons. The sludge transfer process includes slurrying of the sludge prior to transferring it to the ESP tanks. Thus the blended sludge that will be received in the ESP tanks will remain subcritical.

As stated above, the review covered wastes generated in 1992 and earlier. Wastes generated after 1992 are expected to continue to contain sufficient neutron poisons that there is no risk of criticality. However, the adequacy of neutron poisons in the waste sludges received since 1992 must be verified before these sludges are fed to the ESP process.

During aluminum dissolution, some uranium will also be dissolved, but a large majority of the iron, manganese, and plutonium will remain in the sludge [11]. Dissolution of the uranium will not risk criticality in the aluminum dissolution tank. The continued presence of iron and manganese will keep the sludge safely subcritical. The uranium concentration in the supernate will remain small. Reference [12] indicates that the solubility is less than 20 milligrams per liter under normal highlevel waste conditions. Samples have shown concentrations as high as 56 milligrams per liter [13] These concentrations are too low to support criticality in aqueous solutions. 
DISCUSSION (continued)

ESP Criticality Safety Basis (continued)

Subsequent treatment of the aluminum dissolution solutions requires additional evaluation [14]. The disparity between different maximum uranium solubility information reinforces the need for further study. Also, the draft SAR Hazard Analysis and Chapter 3 exclude aluminum dissolution [15]. Thus operation of the aluminum dissolution process will require revision to the Authorization Basis.

\section{ITP Process Description}

ITP uses a combination of chemical precipitation, adsorption, and filtration to remove the majority of radioactive material from high level waste salt solutions. The most abundant salt-solution radioisotope, ${ }^{137} \mathrm{Cs}$, is precipitated with sodium tetraphenyl borate (STPB). At the same time, ${ }^{90} \mathrm{Sr}$, uranium isotopes, and plutonium isotopes are adsorbed on monosodium di-titanate particles. The resulting slurry is filtered into two separate streams. These are the decontaminated salt solution (filtrate) and the highly radioactive precipitate. The filtrate is treated to remove volatile organic materials, and transferred to the saltstone facility. (Current plans are for the filtrate to be held in the filtrate hold tanks pending transfer to Saltstone. Until facility modifications are completed, the filtrate will be routed from the hold tanks to Tank $50 \mathrm{H}$ prior to transfer to Saltstone.) After three precipitation batches in Tank 48, the precipitate is washed with water to remove soluble saits. The washed precipitate is transferred to another high level waste tank (Tank 49H) for storage and feed to the DWPF vitrification facility. Additional detail is available in reference [1].

\section{ITP Criticality Safety Basis}

In ITP, one of the precipitants, monosodium di-titanate, adsorbs uranium and plutonium, the two main fissionable elements present in the high level waste. (Note: Monosodium di-titanate is commonly referred to as sodium titanate, monosodium titanate, or MST, in the ITP facilities and organizations. In criticality safety considerations, it is important to emphasize that the di-titanate is the chemical referred to, since the titanium is the dominant neutron absorber in this material.) The sodium di-titanate also has the beneficial effect of being a neutron absorber. References [16, 17, and 18] show the limiting conditions for fissile materials adsorbed on the sodium di-titanate for criticality safety. Based on these references, the ITP process chemistry [19,20, and 21], and known limitations on fissile material enrichment in the high-level waste tank farms [22], reference [2] demonstrates that criticality due to adsorption on the sodium di-titanate is not credible.

An additional conservatism of the process is not readily quantifiable. The tetraphenyl-borate moiety includes one boron atom. The boron will act as a strong neutron absorber. But the concentration of the tetraphenyl-borate will vary during the process, so that the degree of neutron absorption by the boron in tetraphenyl-borate can not be quantified. 
DISCUSSION (continued)

ITP Criticality Safety Basis (continued)

Oxalic Acid Effects

Cleaning of the ITP filters or other equipment with oxalic acid may dissolve the sodium di-titanate. If this dissolution were to leave undissolved fissile material behind, this could provide a concentrating mechanism for fissile materials. Reference [4] shows that this will not occur. The fissile materials in ITP can not concentrate sufficiently on the sodium di-titanate for this mechanism to leave undissolved fissile material. The fissile materials would dissolve completely in the oxalic acid before the sodium di-titanate is fully dissolved.

Tri-Butyl Phosphate Effects

Addition of tri-n-butyl phosphate (TBP) to the ITP process was evaluated in reference [3]. This reference shows that the chemistry of uranium and plutonium in alkaline waste solutions is significantly different from the chemistry that is encountered in the acidic solutions used in solvent extraction for actinide materials. In alkaline conditions, the uranium and plutonium solubilities are significantly lower, and the complexing of actinides with TBP is negligible. These differences preclude the introduction of any risk of criticality being caused solely by use of TBP in the ITP process. Reference [3] also shows that the interaction of the TBP with normal ITP materials does not risk additional concentration of fissile materials (beyond that already possible in the sodium di-titanate).

Suspended Solids from Salt Dissolution

During the salt dissolution process, some insoluble solids may be suspended in the solution. Fissile materials in these solids could be transferred to the precipitation tank. As discussed below for Tank $41 \mathrm{H}$ salt dissolution, the solids will have sufficient neutron absorbers that they can not cause or contribute to a criticality. This is necessary to ensure that salt dissolution does not create a nuclear criticality risk. It is necessary that the presence of sufficient neutron absorbers be documented before salt dissolution begins in a given salt tank.

\section{Tank $41 \mathrm{H}$ Salt Dissolution Process.}

Salt dissolution involves the addition of water to the high level waste salt tanks, and may include agitation of the solution to enhance the salt dissolution rate. If the solution is not agitated, a layer of saturated solution covers the salt surface, restricting the dissolution rate. Also, insoluble materials in the salt form a layer on the salt surfaces, further restricting dissolution.

In tank $41 \mathrm{H}$, agitation for salt dissolution will be provided (if required) by inserting long-shaft slurry pumps, so that the pump motor is above the tank top, but the pump volute can be lowered to within a few inches of the salt surface. The pump is rotated so that the discharge streams provide a strong jet of solution with sufficient agitation to disnupt the layer of concentrated salt solution, and suspend insoluble solids that may otherwise accumulate on the salt surface. 
DISCUSSION (continued)

\section{Tank 41 Salt Dissolution Criticality Safety}

During salt dissolution, some of the suspended insoluble solids may stay suspended until the solution is transferred to the ITP process. Others may settle in low points in the tank that may be sheltered from the agitation. These solids will contain residual fissile materials deposited in the salt cake. In tank 41, insoluble solids may contain several tens of kilograms of fissile materials [23]. These solids will also contain significant quantities of neutron absorbing materials. Much of the solids content comes from sludge solids entrained with the solutions that were concentrated to form the solid salt. These materials are expected to provide sufficient neutron absorption to make criticality in the salt tanks impossible. However, other considerations, such as the precipitation of slightly soluble (up to $20 \mathrm{mg} /$ liter [12], or $56 \mathrm{mg} /$ liter [13]) uranium makes it necessary to verify that sufficient absorbers are present.

Elements that have been evaluated for neutron absorption in the waste tanks, and that may be present in insoluble portions of the saltcake, include iron $[7,8,9$, and 24], manganese $[7,8$, and 9], chromium [9, 24, and 25], zinc [24 and 25], and sodium [9 and 24].

Existing samples [24 and 26] show the presence of sufficient neutron absorbers in upper portions of the tank $41 \mathrm{H}$ saltcake. Current sample data is not sufficient by itself to demonstrate the presence of adequate neutron absorbers for dissolution of the entire tank $41 \mathrm{H}$ sait volume. According to reference [24], "Salt dissolution can proceed without criticality controls but with a characterization program that demonstrates the continued presence of neutron absorbers." Demonstrating that salt dissolution will remain subcritical requires that the presence of neutron poisons be demonstrated. Sampling the insoluble solids in tank $41 \mathrm{H}$, both in and on top of the salt, is one method for demonstrating the continued presence of sufficient neutron poisons.

Demonstrating their presence by process knowledge is another possibility, but requires extensive knowledge of the chemistry of materials in the high level waste mixtures.

\section{CRITICALITY SAFETY REOUIREMENTS AND RECOMMENDATIONS}

\section{ITP}

The references considered in this report show that the materials in ITP will be inherently subcritical. No actions are currently required to maintain subcriticality within these processes. However, it is prudent to verify that the data and assumptions underlying this evaluation continue to be valid. For this reason, samples from the ITP process should be analyzed to verify the quantities of fissionable nuclides and neutron absorbers. These samples are not necessary to demonstrate the criticality safety basis. They will provide continued reconfirmation of the existing basis.

\section{ESP}

The references considered in this report show that the ESP process itself will be subcritical. The materials in ESP are inherently subcritical in the ESP tanks. However, it is prudent to verify that the data and assumptions underlying this evaluation continue to be valid. For this reason, samples from the ESP process should be analyzed to verify the quantities of fissionable nuclides and neutron 


\section{CRITICALITY SAFETY REQUIREMENTS AND RECOMMENDATIONS (continued)}

ESP (continued)

absorbers. These samples are not necessary to demonstrate the criticality safety basis. They will provide continued reconfirmation of the existing basis. The safety of subsequent operations that may affect the aluminum dissolution solution chemistry, such as high level waste evaporation, is not adequately demonstrated for the aluminum dissolution solutions.

Tank 41H Salt Dissolution

For salt dissolution in tank $41 \mathrm{H}$, the continuing presence of insoluble neutron absorbers must be demonstrated. This is necessary to show that sufficient insoluble neutron absorbers will be present to keep the solids inherently subcritical.

\section{CONCLUSION}

ITP and ESP may be conducted safely: the materials involved are inherently subcritical. They will remain safe without criticality safety limits or controls. However, criticality safety of subsequent evaporation of the ESP aluminum dissolution solutions is not adequately demonstrated. During salt dissolution, fissile materials precipitated in the salt are expected to remain safely subcritical due to the presence of non-soluble neutron absorbing materials. Prior to salt dissolution, the continuing presence of sufficient non-soluble neutron absorbers must be adequately demonstrated. Sampling and evaluation are planned for the ESP and ITP processes, to provide additional confirmation that the material compositions remain in ranges that are inherently subcritical.

\section{REFERENCES}

[1.] WSRC-SA-15 (ITP/ESP SAR Addendum), Rev. 8, 1995.

[2.] WSRC-TR-94-004, "Nuclear Criticality Safety Bounding Analysis for the In-Tank. Precipitation (ITP) Process, Impacted by Fissile Isotopic Weight Ratios (U)", C. E. Bess, April 22, 1994.

[3.] WSRC-TR-94-0134, "The Effects of Tri-n-Butyl Phosphate and its Degradation Products, Di-n-Butyl Phosphate and Mono-n-Butyl Phosphate on the Solubility of Actinides in Allaline Salt Solution (U)", D. T. Hobbs, June 6, 1994.

[4.] IWT-LWP-91-044, "Dissolution of Sodium Titanate and Fissile Materials with Oxalic Acid", D. D. Walker, November 1, 1991.

[5.] HLW-HLE-94-0388, “Assessment of Criticality Safety Parameters Based on Estimated Waste Tank Sludge Contents (U)", J. S. Clemmons to M. C. Chandler, February 2, 199.4.

[6.] SW 16.8-CHEM-1, "Chemistry Manual (U)", Rev. 6, January 10, 1996, sections 8.21 through 8.26. 


\section{REFERENCES (continued)}

[7.] WER-WME-921143, 'Nuclear Criticality Safety Analysis WM-92-3, Minimum Safe Ratios of Fe and Mn to U-235 in an Infinite System (U)", J. S. Clemmons and A. Q. Goslen, September 18, 1992.

[8.] WER-HLE-921353, 'Nuclear Criticality Safety Analysis WM-92-5, Minimum Safe Ratios of Fe and Mn to Pu-239 in an Infinite System (U)", J. S. Clemmons and A. Q. Goslen, November 25, 1992.

[9.] EPD-CTG-960046, "Metal Poisons in Waste Tanks", T. G. Williamson, August 26, 1996.

[10.] WSRC-TR-93-872, “Canyon Transfer Neutron Absorber to Fissile Material Ratio Analysis (U)”, D. K. Strege, August 9, 1993.

[11.] WER-HILE-930561, "Effect of ESP on Waste Tank Sludge U, Pu, Fe, and Mn Content", J. S. Clemmons to M. C. Chandler, February 10, 1993.

[12.] WSRC-TR-93-454, "Solubility of Uranium in Alkaline Salt Solutions (U)", D. T. Hobbs and T. B. Edwards, March 29, 1994.

[13.] WSRC-TR-940224, "Tank 41 Bounding Uranium Enrichment (U)", W. S. Cavin, July 12, 1994.

[14.] WSRC-TR-93-081, "Evaluation of Potential Accumulation of Uranium and/or Plutonium in the HLW Evaporator Systems (U)", G. K. Georgeton and M. C. Chandler, February 1993.

[15.] Personal communication, Robert Griffith to A. Q. Goslen, "Comments on Draft ECS-CRTS-97-0008", March 10, 1997.

[16.] WMR-WMT-920788, "Nuclear Criticality Safety Analysis WM-92-1, Maximum Safe Loading of U-235 on Monosodium Dititanate, Rev. 1 (U)", A. Q. Goslen, July 1, 1992.

[17.] WMR-WMT-920979, 'Nuclear Criticality Safety Analysis WM-92-2, Maximum Safe Masses at Various U-235 Loadings on Monosodium Dititanate, Rev. 1 (U)",

A. Q. Goslen, July 27, 1992.

[18.] WER-HLE-930553, "Nuclear Criticality Safety Analysis WM-93-1, Determination of the Safe Accumulated MST Mass for any MST Mass Addition in the ITP Process (U)", A. Q. Goslen and C. E. Bess, February 22, 1993.

[19.] WSRC-RP-92-1273, "Fissile Solubility and Monosodium Titanate Loading Tests (U)", D. T. Hobbs and S. D. Fleischman, February 12, 1993.

[20.] WSRC-RP-92-93, "Plutonium and Uranium Adsorption on Monosodium Titanate (U)", D. T. Hobbs and D. D. Walker, August 13, 1992. 
REFERENCES (continued)

[21.] WSRC-TR-93-056, "Solubility of Plutonium and Uranium in Alkaline Salt Solutions (U)", D. T. Hobbs, T. B. Edwards, and S. D. Fleischman, February 12, 1993.

[22.] WER-WMT-920871, "Salt Tank Uranium Enrichment (U)", J. B. Justice and K. P. Vanevenhoven, June 22, 1992.

[23.] SRT-CTS-82-231, "Scoping Estimates of 2H System Uranium Content", W. S. Cavin, November 11, 1992.

[24.] N-NCS-H-00034, "Nuclear Criticality Evaluation, Minimum Safe Ratios of Inherent Saltcake Metals to Uranium (U)", R H. Ross, October 14, 1996.

[25.] WER-HLE-930861, "Nuclear Criticality Safety Analysis WM-93-2, Minimum Safe Ratios of $\mathrm{Cr}$ and $\mathrm{Zn}$ to Pu-239 and U-235 in an Infinite System (U)", A. Q. Goslen and D. K. Strege to M. C. Chandler, July 12, 1993.

[26.] WSRC-TR-96-0410, Rev. 0, "Final Report on the Analytical Results for Tank Farm Samples in Support of Salt Dissolution Evaluations (U)", D. T. Hobbs to S. D. Fink, December 12, 1996. 